\title{
REGIONAL ECONOMIC DEVELOPMENT AND PARI-MUTUEL RACING: THE ODDS
}

\author{
Margaret A. Ray*
}

\begin{abstract}
For many years regions have benefited from the existence of pari-mutuel horse racing tracks. Significant government revenue has been generated, racing and horse related industry has been developed, and tourism has been greatly increased for these regions as a direct result of the existence of a pari-mutuel race track. Supporters of racing point out that the race tracks provide jobs and revenue for the area, and that the development which accompanies the tracks does not lead to some of the negative externalities associated with industrial development.

Recognizing these benefits, many states are contemplating or have recently passed laws to allow pari-mutuel betting. These states hope that pari-mutuel race tracks will bring economic development to and provide govemment revenue for the region. This paper develops a theoretical model and uses empirical analysis to identify the factors which determine the success or failure of pari-mutuel horse racing tracks.
\end{abstract}

\section{INTRODUCTION}

As of 1987, 27 states sanctioned pari-mutuel horse racing and had operating race tracks (see Table 1). Pari-mutuel taxes generated close to 650 million dollars for state governments in 1987 (Statistical Abstract of the United States, 1989).

TABLE 1

States With Pari-Mutuel Racing 1987

Alabama
Arizona
Arkansas
California
Delaware
Florida
Indiana
Illinois
Kentucky
Louisiana
Maryland
Massachusetts
Michigan
Minnesota

Montana

Nebraska

New Hampshire

New Jersey

New Mexico

New York

Ohio

Oklahoma

Oregon

Pennsylvania

Washington

West Virginia

Wyoming

Source: 1988 American Racing Manual




Benefits from pari-mutuel horse racing tracks include significant government revenue, the development of racing and horse related industry, and tourism. Supporters of racing point out that race tracks provide jobs and revenue for the area, and that the accompanying development is free of the negative externalities associated with heavy industrial development [Kopp Du Teil (1990)]. For example, horse breeding firms enhance rather than deplete the soil, are aesthetically pleasing, revitalize the existing agricultural sector, and bring tourism and service industries to the area.

Arguments against horse racing and other forms of gambling are made by religious groups and animal rights advocates [Kopp Du Teil (1990)]. Fear of increased crime, competition with dog racing and inhumane treatment of horses are the center of arguments against pari-mutuel horse racing. Some religious groups, which represent large constituencies, oppose gambling. They and others also believe that there is a correlation between horse racing, gambling and crime and corruption. On these bases, opponents argue against sanctioning pari-mutuel racing.

Recognizing the benefits created by existing tracks, many states are contemplating or have recently passed laws to allow pari-mutuel racing. These states hope pari-mutuel race tracks will bring economic development and provide government revenue for their region. But some areas have already found that race tracks are not the expected panacea. The pari-mutuel racing pie may simply not be large enough for everyone to have a piece. Alabama's first race track, the Birmingham Turf Club, filed for bankruptcy, as did Oklahoma's Will Rogers Downs. A Kansas race track was forced to cancel its opening day due to insufficient entries. And Arkansas' Hot Springs track has needed tax breaks to remain solvent since the opening of Oklahoma's Remington Park [Kopp Du Teil (1989)]. Even so, many states today are considering building new tracks allowed by pari-mutuel legislation.

Texas passed pari-mutuel racing legislation in 1987. Since then, the only track to open is G. Rollie White Downs, a class II facility. The track lost $\$ 28,000$ per week during its first month in operation [Kopp Du Teil (1990)]. Missouri voters passed pari-mutuel legislation in 1984 but race tracks have yet to be built. In these two states the problem seems to be the necessary conditions for building a track set forth in the law.

Wisconsin is targeting May 1992 as the opening date for its first pari-mutuel horse racing track. Wisconsin track proponents have had to overcome lobbying efforts of greyhound enthusiasts in their efforts to build a horse track [Kopp Du Teil (1990)]. Kansas also had to contend with the opposition of dog racing organizations. In Kansas, dog and horse racing enthusiasts compromised and built a combined dog/horse race track (the first of its kind) that was set to open May 
1990. Other states which have passed pari-mutuel legislation but do not currently have race tracks include Tennessee, Virginia, and Indiana. These states, as well as states with an existing horse racing industry, respond to the changing status of pari-mutuel racing. How many tracks should a state allow, and where? How many race days should be granted to state tracks? What type and quality of horses should be raced? These are questions faced by states desiring pari-mutuel horse racing.

Economists have investigated many issues relating to the economics of parimutuel gambling. Past studies have addressed the betting behavior of individuals [Gruen (1976)], the public choice issue of legislating pari-mutuel racing [Herch and McDougall (1988)], gambling tax incidence [Mason, Shapiro and Borg 1989)] and regional development through lottery revenues [Peppard (1987)]. But the economics literature has not addressed regional development issues often used as arguments for the legalization of racing.

The question of the regressivity of gambling tax incidence is important when considering the use of lotteries, pari-mutuel racing or other forms of gambling as a means of revenue generation and regional economic development. In a 1977 study, Suits finds that gambling taxes are in fact regressive with the most regressive being numbers games, lotteries and off track betting, respectively. Mason, Shapiro and Borg (1989) conclude that gambling taxes are regressive, with increased regressivity for out-of-state gamblers. The regressivity of the tax for those living in the Las Vegas area is mitigated by the benefits local residents receive from economic development brought about by the gambling.

Despite general agreement as to the regressivity of gambling taxes, the use of lotteries and gambling taxes as a source of government revenue has been on the rise. Peppard, in his 1987 study, addresses the increased interest in lotteries as a way for states to increase revenues. Some states have found that lotteries don't generate the expected revenues and have turned to pari-mutuel racing (e.g. Missouri).

This paper looks at state sanctioned pari-mutuel horse racing, develops a model and uses empirical analysis to identify factors affecting the success or failure of pari-mutuel horse racing in generating revenue. It is important for states contemplating building new tracks (with the hope of government revenue and regional development) to understand the factors influencing the viability of parimutuel horse racing in their state.

\section{A MODEL OF RACE TRACK SUCCESS}

From the perspective of both the state and the race track, success depends directly on the track handle (defined as the total amount of money legally bet at 
pari-mutuel tracks). For the track, the handle is equivalent to total revenue (excluding concession earnings). For the state, the track handle is the base used to calculate the government's tax share (average tax is 7.5\%; Suits, 1977). For both, it is an indication of economic activity associated with the track.

Pari-mutuel race tracks provide betting services. The output produced is measured as the number of bets. The institutional structure of race tracks generates the market for bets depicted in Figure 1. All bets are denominated by $\$ 2$. The odds and payoffs for races are posted for $\$ 2$ bets (e.g., a $\$ 100$ bet is treated as fifty $\$ 2$ bets). A track must provide the number of $\$ 2$ bets demanded by bettors, resulting in a perfectly elastic supply curve. Once betting is opened, it is the handle for the race which determines the track's profit or loss (assuming the marginal cost of a bet transaction is minimal). Therefore, the level of demand determines the equilibrium quantity of $\$ 2$ bets and thus the track's handle, as depicted in Figure 1.

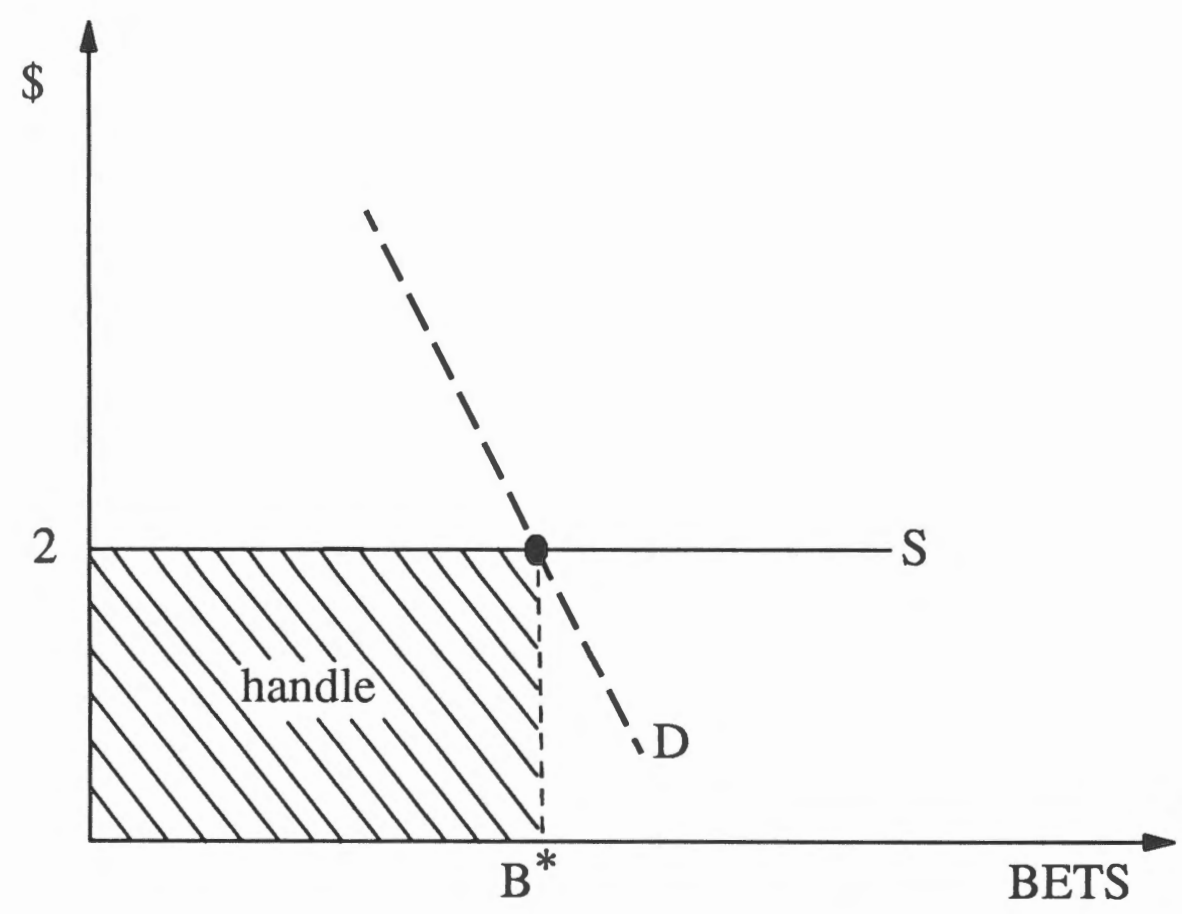


The determinants of demand for bets include: bettor tastes and preferences, the number of bettors, bettor income, price and availability of complements and substitutes, and bettor expectations.

A bettor's tastes and preferences for betting on a race are determined by factors such as the breed and quality of the horses racing, the pre-race odds, the track conditions, availability of information (e.g., the horses' records and workout times, jockey reputation) and other factors that may influence the bettor's perception of the probability of winning the bet and/or the payoff associated with winning. Individuals may prefer to bet Quarter Horses versus Thoroughbreds, long shots versus sure things, or experienced jockeys versus novices.

The number of bettors attending the track and the number of $\$ 2$ bets per bettor also influence the level of demand. Ceteris paribus, as the number of bettors or the number of bets per bettor increases, so will the track handle. Bets on horse races are assumed to be normal goods, increasing with bettor income [Gruen (1976)].

Bets on horse races have both substitutes and complements. Substitutes for bets on horse races may include bets on dog races and on lotteries as well as other available legal and illegal betting opportunities. Complements include race tip sheets, racing programs, concessions and other services a bettor requires for a trip to the track.

Finally, the level of demand is a function of bettor expectations. Obviously, a bettor's expectations with regard to the outcome of the race or the expected payoff will affect her decision to bet.

The success or failure of a state's horse racing industry depends on the level of demand for the betting services provided. Given that a state is about to implement horse racing, it is important to understand the factors that will determine the success of the endeavor. It is also important for states that have historically relied on revenue from horse racing to understand how those revenues may be affected by increased competition for bets.

\section{EMPIRICAL ANALYSIS}

The purpose of this study is to develop a total revenue function incorporating the determinants of a successful pari-mutuel flat racing industry.

To estimate a total revenue function which is applicable to all states, it is first necessary to correct for self-selection bias in the sample. Because only states which already sanction pari-mutuel racing can be used to estimate the equation, a classic self-selection problem exists. To control for self selection in this study, the Heckman correction procedure is employed [Heckman (1979)]. The Heckman 
procedure is widely used in the empirical literature to control for self-selection problems of this nature [Dauffenbach and Grimes (1989); Murnane, Newstead and Olsen (1985); Willis and Rosen (1979)]. The two-stage procedure incorporates the probability of a state's sanctioning pari-mutuel racing into a regression equation to be estimated.

To calculate the Heckman correction coefficient (Lambda), a probit equation is estimated to determine the probability of a state's sanctioning pari-mutuel racing. Voters' willingness to pass legislation allowing pari-mutuel racing is a function of existing economic and social conditions. In addition, a state's acceptance of other activities ( e.g. pari-mutuel dog racing) indicates its attitude toward pari-mutuel horse racing.

Definitions of the independent variables included in the probit equation are found in Table 2. The Debt, Education and Travel variables are included to proxy a state's economic conditions. The size of a state's debt indicates its fiscal status. Presumably, the larger a states debt, the greater the perceived need (by the voters) to generate increased revenues through the institution (or retention) of pari-mutuel racing [Peppard (1987)].

Pari-mutuel tax revenues are earmarked for educational expenditures in many states. Thus, the lower state expenditures on education, the higher is the probability that the state sanctions pari-mutuel racing, due to the voters perception of the need for pari-mutuel tax revenue [Peppard (1987)]. Whether the anticipated pari-mutuel revenues will be generated or whether they will be used to reduce the state's debt or increase funding for education is not known, nor is it important for this estimation. What is important, from a public choice perspective, is the voters' perceived need to implement or retain pari-mutuel racing to generate revenues.

The travel variable is included to measure the state's reliance on tourism. If voters perceive a need for, or benefit from, expanding the tourism industry in their state, pari-mutuel racing presents an opportunity. Voters in states with important, well-developed tourism industries may not see the need for pari-mutuel racing to boost tourism. Voters in states that lack a significant tourism industry may vote for pari-mutuel racing as a way to lure tourists.

Councils represents the political power of the state's horse industry. The existence of an effective horse industry lobby should increase the probability of passing legislation allowing pari-mutuel racing.

The Church and South variables enter the probit equation as measures of the social conditions of a state as they relate to the acceptance or rejection of parimutuel racing. As the percent of religious adherents increases, the probability of pari-mutuel horse racing should decline as a result of religious anti-gambling doctrines. It has been shown that, as a region, the South is culturally different 
TABLE 2

Definition Of Variables

Variable (Expected Sign)

Definition

\section{Probit Equation}

Tracks

1 = State sanctions pari-mutuel horse racing;

$0=$ Otherwise.

Debt (+)

Total outstanding state debt per capita.

Education (-)

Direct general expenditures on education per capita.

Travel (-)

Spending on overnight trips and day trips of 100 miles or more.

Councils (+)

$1=$ State has horse industry political lobby; $0=$ Otherwise.

Church (-)

South (-)

Christian church adherents as a percent of population.

Dogs (+)

$1=$ South census region;

$0=$ Otherwise.

1 = State sanctions pari-mutuel dog racing;

$0=$ Otherwise.

$\underline{\text { Regression Equation }}$

Handle

Total state pari-mutuel handle (in millions).

Number (+)

Number of pari-mutuel horse tracks in state.

Days (+)

Total number of race days allowed by state.

Stakes ( + )

Racing (-)

Number of stake races with a purse of greater than $\$ 200,000$.

1 = State sanctions other pari-mutuel racing;

$0=$ Otherwise.

Lottery (-)

$1=$ State sponsors lottery;

$0=$ Otherwise .

Income (+)

Total real personal income per capita.

Population (+)

Resident population per square mile.

Lambda

Inverse of Mills' Ratio (Heckman correction). 
from the rest of the nation and can therefore be expected to differ from the rest of the country in their acceptance of pari-mutuel horse racing [Rubin (1980)].

The Dogs variable represents a state's acceptance of other types of gambling and racing. States that sanction pari-mutuel dog racing are expected to have a higher probability of accepting pari-mutuel horse racing. The results of the probit equation are reported in Table 3.

TABLE 3

Probability of Sanctioning Racing

(Dependent Variable $=$ Tracks)

\begin{tabular}{lcl}
\hline \hline Variable & Coefficient & $\mathrm{t}$ - Ratio \\
\hline Constant & 1.73258 & 1.08 \\
Debt & 0.00208 & $2.58^{* * *}$ \\
Education & -0.92663 & 1.50 \\
Travel & -0.00050 & $2.33^{* * *}$ \\
Councils & 0.86607 & $1.67^{* *}$ \\
Church & -0.02414 & 1.15 \\
South & -0.95986 & $1.76^{* *}$ \\
Dogs & 1.10096 & 0.01 \\
\hline
\end{tabular}

Log Likelihood

$\mathbf{R}^{2}$

$\mathrm{N}=50$

$1 .=27$

$0=23$

\section{$-23.64$}

.74

****Significant at the .01 level, one-tailed test.
${ }^{* *}$ Significant at the .05 level, one-tailed test.

The results of the probit estimation indicate that fiscal, economic, political, and cultural considerations significantly affect the probability of adopting parimutuel horse racing as expected. The pseudo- $\mathrm{R}^{2}$ (which measures the predictive probability of the model) equals .74. This equation is used to calculate the Heckman coefficient (Lambda - the inverse Mill's ratio) that enters the regression equation below. 
Based on the discussion of race track success above, the following total revenue function for states with pari-mutuel horse tracks is estimated using ordinary least squares:

\section{Handle $=\mathrm{A}_{0}+\mathrm{B}_{1}$ Number $+\mathrm{B}_{2}$ Days $+\mathrm{B}_{3}$ Stakes $+\mathrm{B}_{4}$ Racing $+\mathrm{B}_{5}$ Lottery +

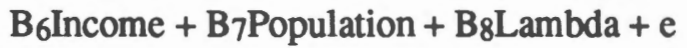

The definition of each variable is included in Table 2. Use of the Heckman procedure allows variables from the probit equation to appear in the regression equation [Heckman (1979)]. Each variable proxies an aspect of the determinants of demand for betting services.

Days is included to reflect the availability of racing to consumers in a state. The number of tracks and the number days the tracks are allowed to operate determine the public's access to pari-mutuel races. Greater access should result in higher handles.

The Stakes variable is included to measure consumer tastes and preferences. The more stake races offered in a state, the higher will be the quality of the racing, as better horses are brought to compete for larger purses. High quality races decrease uncertainty and attract bettors, increasing the handle.

Harness racing, Dog racing and Lotteries are substitute forms of legal gambling. The availability of these alternative forms of gambling and racing are expected to decrease the demand for pari-mutuel horse racing and thereby decrease track handles. The Racing and Lottery variables are included to control for the availability of substitutes.

Total real personal income is included in the equation to measure the ability of consumers to bet. As consumer incomes increase, the ability to afford gambling services increases. Thus, as per capita state income increases, total track handles should increase.

The population density is also included to measure the number of potential bettors. Holding the other factors constant, the higher the population density in a state, the more potential bettors for any given pari-mutuel track.

\section{THE RESULTS}

The racing data used for the estimation (Tracks, Handle, Number, Days, Stakes) are contained in The 1988 American Racing Manual. The state economic variables (Debt, Education, Church, Lottery, Income, Population) are found in the 1989 Statistical Abstract of the United States. The remaining data (Councils, Racing) are from the 1988 Horse Industry Directory. The racing data encompas- 
ses race tracks where flat races take place. Unless otherwise noted, all data is for 1987. The means and standard deviations of variables are reported in Table 4.

TABLE 4

Means and Standard Deviations of Variables

\begin{tabular}{lrc}
\hline \hline Variable & Mean & Standard Deviation \\
\hline Tracks & 0.54 & 0.50 \\
Debt & 4.23 & 4.08 \\
Education & 1.20 & .39 \\
Councils & 0.66 & 0.48 \\
Church & 50.50 & 11.70 \\
South & 0.32 & 0.47 \\
Dogs & 0.14 & 0.36 \\
Handle & 163.52 & 368.55 \\
Number & 1.80 & 2.63 \\
Days & 147.38 & 186.58 \\
Stakes & 2.44 & 6.97 \\
Racing & 0.38 & 0.57 \\
Income & 0.02 & 0.01 \\
Lottery & 0.46 & 0.51 \\
Population & 160.91 & 227.56 \\
\hline
\end{tabular}

The results of the estimated state total revenue function are shown in Table 5. The magnitudes of the regression and standardized (beta) coefficients show how a change in the independent variables is expected to affect track handles. The equation is robust, with a significant F-statistic. The $\mathrm{R}^{2}$ equal to .96 indicates that the equation explains a significant portion of the variation in state racing handles.

The estimated coefficients for the availability variables (Number and Days) show how a state can best provide access to racing in order to maximize revenue. 
TABLE 5

Total Revenue Equation

(Dependent Variable $=$ Handle)

\begin{tabular}{lrrr}
\hline \hline & & & \\
Variable & Coefficient & $\begin{array}{c}\text { Beta } \\
\text { Coefficient }\end{array}$ & t-Ratio \\
\hline Constant & -137.31 & -50605.60 & $1.36^{*}$ \\
Number & 7.74 & 1084.63 & 0.54 \\
Days & 0.43 & 0.85 & $2.61^{* * *}$ \\
Stakes & 43.99 & 2326.04 & $9.72^{* * *}$ \\
Racing & -60.51 & -39124.49 & $2.05^{* * *}$ \\
Lottery & 1.72 & 1242.95 & 0.06 \\
Income & 8789.48 & 323963285.40 & $1.33^{*}$ \\
Population & 0.03 & 0.05 & 0.39 \\
Lambda & -0.08 & & 0.49 \\
\hline
\end{tabular}

F-statistic

117.73

$\mathbf{R}^{2}$

0.96

$\mathbf{N}$

27

*** Significant at the .01 level, one-tailed test.
Significant at the .10 level, one-tailed test.

The number of tracks is not found to affect the state's pari-mutuel handle significantly, while increasing the number of racing days is found to increase total state handle. This indicates that more race days allowed by state authorities will enhance the state's handle but that in doing so it is not necessary to increase the number of race track sites.

The Stakes variable is statistically significant, indicating that the quality of racing is very important in determining the state handle. States which ensure high quality racing in their state have increased total state handle, ceteris paribus.

Racing and Lottery are included to control for available legal substitutes for horse racing in a state. A priori, each is expected to effect state handles negatively. However, only Racing is found to have a significant effect on track handles. This suggests bettors at flat horse racing tracks prefer gambling on racing and do 
not see lotteries as close substitutes. States must be aware of the specific nature of horse track bettor preferences when considering alternative and competitive forms of betting.

The Income coefficient is statistically significant and conforms to expectations. As per capita income in a state rises, state track revenue also rises. This indicates that, an increase in the consumer incomes increases total track handle (i.e., betting is a normal good). The population variable, included to control for population density, is not significant.

Lambda is negative, indicating that the sample contains a self-selection bias. Even though Lambda is not significant, Heckman (1979) notes that, in the case of a negative coefficient for Lambda, its inclusion alters the relative magnitude and significance level for the other explanatory variables. Including Lambda corrects for self selection bias and allows the results to be generalized to those states that currently allow racing and those which do not, with equal confidence.

\section{CONCLUSIONS}

It is important for states hoping to develop agriculture and tourism and generate government revenue via pari-mutuel horse racing to understand that simply building race tracks will not best achieve their goals. The results reported here suggest that the income of a state dictates the level of success that can be expected and the number of tracks that will be profitable. Further, states must note that increasing the number of race days, but not necessarily the number of tracks, will increase handles. This goal must be balanced with other factors in determining the number of tracks and number of race days which each track is allowed.

Harness and dog racing in a state are found to be close substitutes for horse racing when estimating the expected handle in a state. Competing forms of racing and legalized gambling must be considered when introducing horse racing into a state in order to maximize total state pari-mutuel taxes.

Finally, a very important factor found to determine the success of a state's pari-mutuel horse racing system is the quality of the racing. States that provide high quality horses, drawn by high prize stake races, experience significantly higher track handles (ceteris paribus). Thus, pari-mutuel race tracks will be most successful when large purses and quality racing are provided.

States that currently allow pari-mutuel racing should expect changes in the state pari-mutuel handle as a result of changes in pari-mutuel systems or economic conditions (in their state or a competing state). States that are currently considering pari-mutuel racing formats (e.g., Texas, Tennessee, and Virginia) must consider how many tracks to build, how many race days to allow, what kind of races to run, and where to locate race tracks. In addition, states must ensure 
that the quality of racing is high in order to maximize revenues. This study provides insights into the factors which influence the success of pari-mutuel racing. States that expect to experience regional development as a result of a parimutuel racing system must do more than allow race tracks to be built if racing is to survive and prosper in the region.

\section{REFERENCES}

Dauffenbach, R.C. and P.W. Grimes. "Self-Selection and Occupational Mobility." International Journal of Manpower. 10 (1989). 11-19.

Gruen, A. "An Inquiry into the Economics of Race-track Gambling." Journal of Political Economy. 84 (1976). 56-64.

Heckman, J. "A Sample Selection Bias as a Specification Error." Econometrica. 42 (1979). 153-161.

Hersch, P. L. and G.S. McDougall. "Voting for 'sin' in Kansas." Public Choice. 57 (1988). 127-139.

Kopp Du Teil, Karen. "Still in the Starting Gate." Equus. 148 (1990). 11-14.

Mason, P.M., S.L. Shapiro and M.O. Borg. "Gaming Tax Incidence for Three Groups of Las Vegas Gamblers." Applied Economics. 21 (1989). 1267-1277.

Murnane, R., S. Newstead and R. Olsen. "Comparing Public and Private Schools: The Puzzling Role of Selectivity Bias." Journal of Business and Economic Statistics. 3 (1985). 23-35.

Peppard, D.M. "Government as a Bookie," Reviewof Radical Political Economy. 19 (1987). 56-68.

Rubin, Louis D. The American South. Baton Rouge: State University Press, 1980.

Suits, D. B. "Gambling Taxes: Regressivity and Revenue Potential." National Tax Journal. 30 (1977). 19-35.

Willis,R. and.S. Rosen. "Education and Self-Selection," Journal of Political Economy. 87 (1979). S7-S36. 